$1-2013$

\title{
Flexible Supercapacitor Sheets Based on Hybrid Nanocomposite Materials
}

Qiang Liu

Cleveland State University

Osama Nayfeh

University of Illinois at Urbana-Champaign

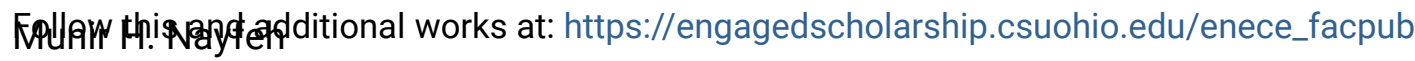

ikersity af llineis at Urbana-Champaian

Stiqutags/agcess to this work benefit you? Let us know!

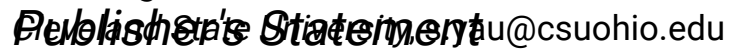

NOTICE: this is the author's version of a work that was accepted for publication in Nano Energy. Changes resulting from the publishing process, such as peer review, editing, corrections, structural formatting, and other quality control mechanisms may not be reflected in this document. Changes may have been made to this work since it was submitted for publication. A definitive version was subsequently published in Nano Energy, 2, 1, (01-01-2013); 10.1016/ j.nanoen.2012.08.007

\section{Original Citation}

Q. Liu, O. Nayfeh, M. H. Nayfeh and S. Yau, "Flexible supercapacitor sheets based on hybrid nanocomposite materials," Nano Energy, vol. 2, pp. 133-137, 1, 2013.

\section{Repository Citation}

Liu, Qiang; Nayfeh, Osama; Nayfeh, Munir H.; and Yau, Siu-Tung, "Flexible Supercapacitor Sheets Based on Hybrid Nanocomposite Materials" (2013). Electrical Engineering \& Computer Science Faculty Publications. 212. https://engagedscholarship.csuohio.edu/enece_facpub/212

This Article is brought to you for free and open access by the Electrical Engineering \& Computer Science Department at EngagedScholarship@CSU. It has been accepted for inclusion in Electrical Engineering \& Computer Science Faculty Publications by an authorized administrator of EngagedScholarship@CSU. For more information, please contact library.es@csuohio.edu. 


\title{
Flexible supercapacitor sheets based on hybrid nanocomposite materials
}

\author{
Qiang Liu ${ }^{a}$, Osama Nayfeh ${ }^{b}$, Munir H. Nayfeh ${ }^{b}$, Siu-Tung Yau ${ }^{a, *}$
}

a Department of Electrical and Computer Engineering, Cleveland State University, Cleveland, OH 44115, USA

'Department of Physics, University of Illinois at Urbana-Champaign, Urbana, IL 61801, USA

\section{Introduction}

The incorporation of inorganic nanomaterials into organic conducting polymers to form hybrid nanocomposite materials appears to be an effective approach for preparing electrochemical energy storage materials [1]. The capacitance of the hybrid materials consists of the pseudocapacitance produced by the polymers and, in most cases, the electric double-layer capacitance generated by the nanomaterials. The hybrid

"Corresponding author. Tel.: +1 216875 9783;

fax: +1 2166875405 .

E-mail address: s.yau@csuohio.edu nature of the materials, when used to construct supercapacitors, has resulted in enhanced energy and power capabilities [2]. To date, conducting polymers such as polyaniline (PANI), polypyrrole and polythiophene have been used to anchor inorganic nanomaterials such as carbon nanotubes (CNT) and nanoparticles for the construction of supercapacitors $[3,4]$ and for studying the properties of the composite materials. Previously, this group has reported the preparation of a composite material consisting PANI and silicon nanoparticles [5]. The material was characterized by depositing the material on single electrodes. In a subsequent work, this group has described a simple approach for constructing flexible sheets of supercapacitors using a composite material made of PANI and carbon nanotubes. Carbon nanotubes were used to 
reduce the internal resistance of the conducting polymer. The capacitor sheets show a specific capacitance of $16 \mathrm{~F} / \mathrm{g}$. Stacks of capacitor sheets were used to light up three light-emitting diodes [6].

In this article, we report the construction and characterization of flexible supercapacitor sheets, whose active electrode material was a nanocomposite material consisting of the conducting polymer, polyaniline, and nanomaterials with quasi-zero, one and two dimensionalities, including carbon nanotubes, silicon nanoparticles, titanium oxide particles and grapheme flakes. The capacitor sheets show a high specific capacitance of $477.1 \mathrm{~F} / \mathrm{g}$. Stacks of capacitor sheets have been used for the first time to power a LED lamp consisting of 12 LEDs to demonstrate the potential of the nanocomposite-based capacitor sheet in illumination applications.

\section{Experimental}

Silicon nanoparticles were made by electrochemical etching of a silicon wafer in hydrofluoric acid and hydrogen peroxide followed by shaking off the particles from the etched wafer using ultrasound in water or organic solvents as described previously [7]. This etching technique can be used to prepare 1-nanometer particles (Si1) and 2.8-nanometer particles (Si2.8), depending on etching conditions. A water-based Si2.8 suspension $(10 \mu \mathrm{M})$ was used in the present work. Single-walled carbon nanotubes (CNT) were purchased from Carbon Solutions. The $50 \mathrm{~nm}$ titanium dioxide particles $\left(\mathrm{TiO}_{2}\right)$ in the form of powder were purchased from Nanostructured \& Amorphous Materials. The $12 \mathrm{~nm}$ flakes of graphene (GR) were purchase from Graphene Supermarket. Polyaniline (PANI) dispersed in xylene was purchased from Sigma-Aldrich.

Flexible capacitor sheets were fabricated using a twostep method described previously [6]. Polyvinyl alcohol (PVA) powder (Sigma-Aldrich) was mixed with water with a ratio of $1: 9$ by weight. The PVA mixture was then mixed with phosphoric acid $\left(\mathrm{H}_{3} \mathrm{PO}_{4}, 85 \%\right)$ with a ratio of $9: 1$ by volume. Films of PVA were formed by first casting the final mixture on a glass surface and then peeling the cast off from the surface after water had evaporated. Free-standing films with a thickness of about $0.3 \mathrm{~mm}$ were used as flexible electrolyte. To prepare the nanocomposite materials, initially $0.4 \mathrm{ml}$ of PANI and $0.003 \mathrm{~g}$ of single-walled CNT were mixed in $99 \% \mathrm{~N}$-dimethylformamide (final volume was $1 \mathrm{ml}$ ) to form the base mixture. Then three individual nanomaterials $(0.6 \mathrm{ml}$ of $\mathrm{Si} 2.8,0.02 \mathrm{~g}$ of $\mathrm{GR}$ or $0.02 \mathrm{~g}$ of $\mathrm{TiO}_{2}$ ) were mixed with $1 \mathrm{ml}$ of the base mixture to form composite mixture, i.e. PANI/CNT/Si2.8, PANI/CNT/GP and $\mathrm{PANI} / \mathrm{CNT} / \mathrm{TiO}_{2}$. A painting brush was used to transfer the composite material to both sides of a PVA sheet to form and define the shape of a capacitor. Painted sheets were put in an oven at $40 \mathrm{C}$ for the water content in to evaporate. The two-dimensional size of the capacitor was about $5 \mathrm{~mm} \times 5 \mathrm{~mm}$. Electrical contacts to the nanocomposite materials were made by either using metallic clips or copper sheets. Figure 1(a) shows a supercapacitor sheet.

Cyclic voltammetry of the nanocomposite materials deposited on single electrodes and galvanostatic chargingdischarging measurements of capacitor sheets were performed using a commercial potentiostat $(\mathrm{CH}$ Instrument $660 C)$. The electrochemical cell used was a conventional three-electrode cell with a commercial $\mathrm{Ag} / \mathrm{AgCl}(3 \mathrm{M} \mathrm{KCl})$ electrode as the reference electrode and a platinum wire as the counter electrode. For voltammetry measurements, the cell potential was scanned at $50 \mathrm{mV} / \mathrm{s}$. Charging-discharging measurements were made at different current densities with cutoff voltages of 0 and up to $2.0 \mathrm{~V}$. Voltammetry measurements were made with electrodes immersed in $0.5 \mathrm{M} \mathrm{H}_{2} \mathrm{SO}_{4}$ aqueous electrolyte. Deionized water $(\sigma=18.2 \mathrm{M} \Omega \mathrm{cm}$, Direct Q3, Millipore) was used to prepare solutions. Phosphate buffer solution (PBS, $100 \mathrm{mM}$ ) was prepared for general use. Highly oriented pyrolytic graphite (HOPG) was used as electrodes to support the nanocomposite materials. Scanning electron microscopy was performed using an Amray 1820 instrument.

\section{Results and discussion}

Scanning electron microscopy (SEM) has been used to study the structures of the nanocomposite materials. The SEM images of the PANI/GR and PANI/CNT/GR nanocomposite materials are shown in Figure 1 (b) and (c), respectively. Figure 1(b) shows that nanoscale flakes of GR are incorporated into a matrix of PANI. A limited amount of pores are present in the material. Figure 1 (c) shows that the incorporation of CNT into the material has created pores with sizes ranging from micrometer to nanometer. The SEM resolution was not high enough to resolve the nanoparticles.

The charge-storing properties of the nanocomposite materials were first characterized qualitatively by performing cyclic voltammetry with single HOPG electrodes, on which equal weights of the nanocomposite materials had
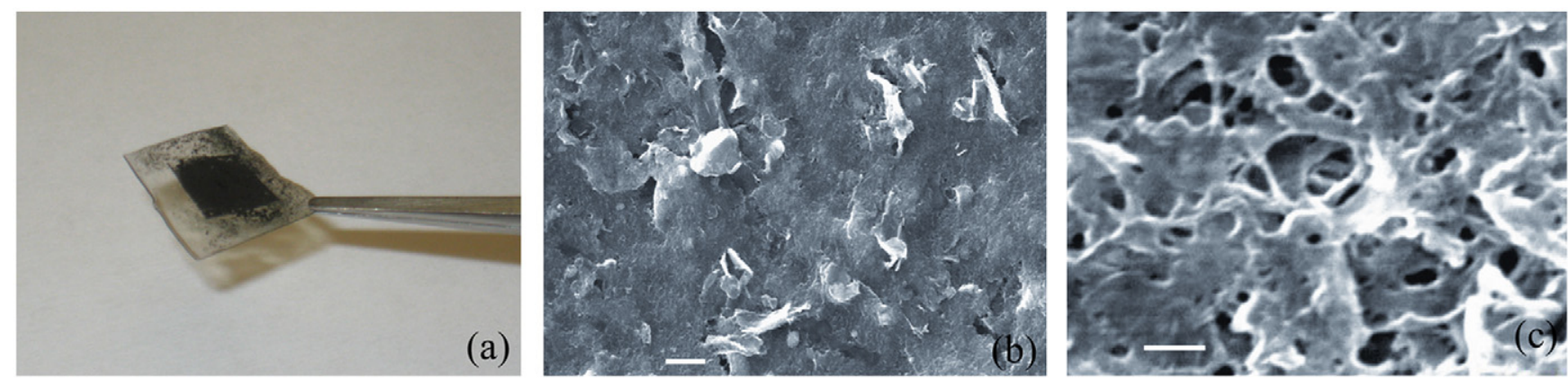

Figure 1 (a) The flexible supercapacitor sheet. (b) SEM image of PANI/GR nanocomposite material. The horizontal bar indicates $10 \mu \mathrm{m}$. (c) SEM image of PANI/CNT/GR nanocomposite material. The horizontal bar indicates $1 \mu \mathrm{m}$. 
been deposited individually on only one side of the electrodes. For comparison purposes, cyclic voltammetry was also performed with single HOPG electrodes, which were coated with the same weight of PANI or the PANI/CNT composite as the three nanocomposite materials. Figure 2(a) shows the voltammogramms (CVs) of the single PANI electrode and the single PANI/CNT electrode. CV1 was obtained with the PANI electrode immersed in $1 \mathrm{M} \mathrm{H}_{2} \mathrm{SO}_{4}$. $\mathrm{CV} 1$ shows three pairs of redox peaks, namely, $A_{1} / C_{1}, A_{2} / C_{2}$ and $A_{3} / C_{3} . A_{1} / C_{1}$ and $A_{3} / C_{3}$ indicate respectively the transition between leucoemeraldine and emeraldine salt and the transition between emeraldine salt and pernigraniline [8]. $A_{2} / C_{2}$ has been attributed to the presence of ortho-coupled polymers [9]. The appearance of the redox peaks indicates that the purchased PANI was functional as conducting polymer and therefore the redox processes of PANI gave rise to pseudocapacitance of the electrode [10]. CV2 was obtained with the PANI/CNT electrode. The three pairs of redox peaks still appear in CV2 with a positive $100 \mathrm{mV}$ shift in potential. Comparing the two CVs indicates that the total current level of the PANI/CNT electrode is increased due to the presence of CNT, which is used in supercapacitors mainly as an electrical conductivity enhancer while contributing an electrical double-layer capacitance [11] component to the total capacitance of the electrode.

The CVs obtained with single electrodes, on which the three nanocomposite materials have been deposited individually, are shown in Figure 2(b). The three CVs, when compared to
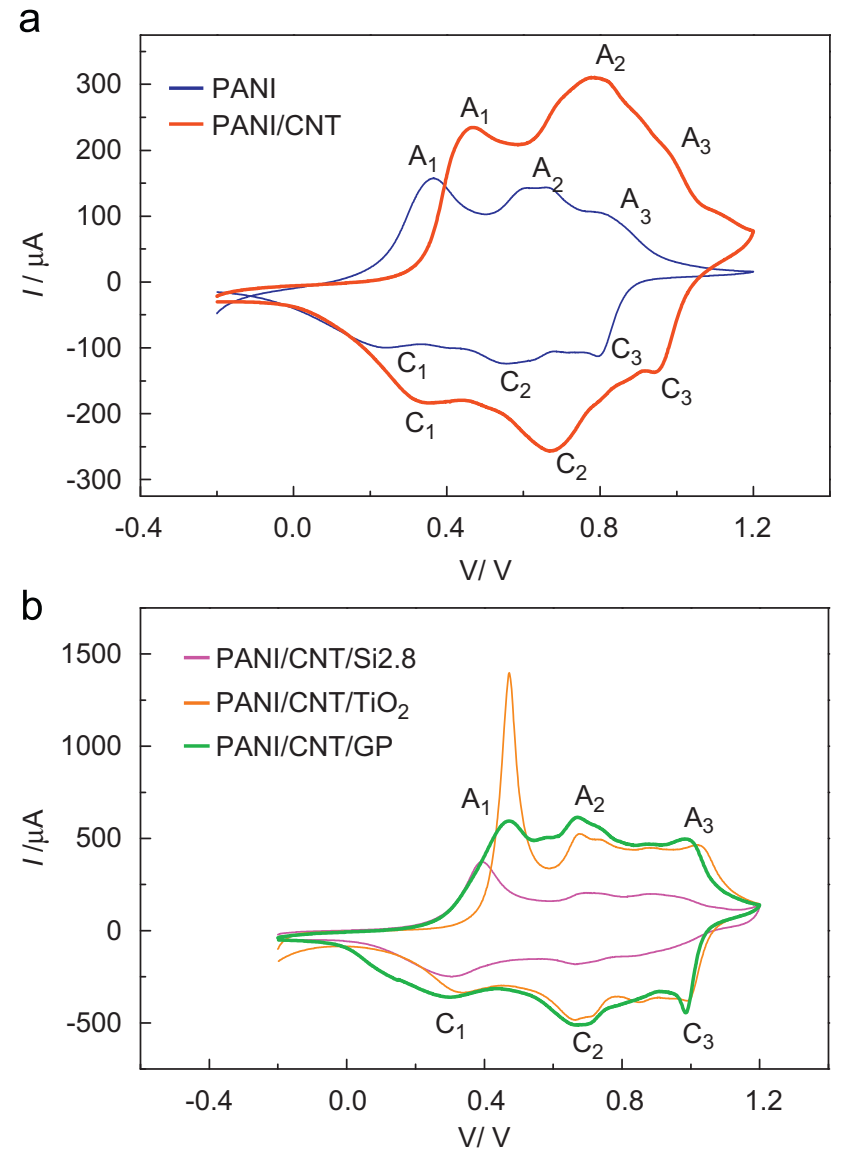

Figure 2 (a) CVs of PANI and PANI/CNT single electrodes. (b) CVs of the three single nanocomposite electrodes. the CVs in Figure 2(a), show enhanced current levels, which are caused by the presence of the nanomaterials. The enhanced current levels indicate enhanced electrode capacitances. Therefore, Figure 2(b) qualitatively indicates the enhanced electrode capacitances produced by the presence of the nanomaterials in the conducting polymer. The change in the peak heights and the shift in the peak potentials as the result of adding the nanomaterials in PANI suggest a possible faradic process associated with the nanomaterials, which is believed to produce only the double-layer capacitance.

The capacitances of the nanocomposite capacitor sheets constructed as described above have been characterized by performing the charging-discharging process of the sheets. The charging-discharging characteristics are presented as Trace 1 in Figure 3(a), (b) and (c) for the PANI/CNT/Si2.8, PANI/CNT/ $\mathrm{GP}$ and $\mathrm{PANI} / \mathrm{CNT} / \mathrm{TiO}_{2}$ composites, respectively. For comparison purposes, capacitor sheets constructed without CNT have been also characterized and the results are displayed as Trace 2 in Figure 3(a), (b) and (c). Trace 2 of Figure 3 indicates a large equivalent series resistance (ESR) of the charge-storing material (the vertical drop in voltage), which in principle reduces the power output of the capacitor sheet [12]. Trace 1, however, shows that the inclusion of CNT in the composite materials effectively reduces ESR due to the increased conductivity provided by CNT. This effect is clearly reflected in the insets of Figure 3, where Trace 1 and Trace 2 are brought together so that the discharging processes occur at the same time for comparison purposes.

The performance of the composite materials as the active material for supercapacitors has been characterized quantitatively. The specific capacitances $C_{S}$ of the capacitor sheets have been evaluated using Trace 1 of Figure 3 according to $C_{S}=I /(m \times d V / d t)$, where $I$ is the discharging current, $m$ is the mass of the electrode material and $d V / d t$ is the rate of change in the discharging potential obtained from the chargingdischarging trace. The estimated values of $C_{S}$ of the PANI/ $\mathrm{CNT} / \mathrm{Si2}$.8, PANI/CNT/GP and PANI/CNT/ $/ \mathrm{TiO}_{2}$ capacitor sheets are $77.18 \mathrm{~F} / \mathrm{g}, 136.84 \mathrm{~F} / \mathrm{g}$ and $477.1 \mathrm{~F} / \mathrm{g}$, respectively. Note that the high value $477.1 \mathrm{~F} / \mathrm{g}$ for the $\mathrm{PANI} / \mathrm{CNT} / \mathrm{TiO}_{2}$ capacitor sheet reflects the fact that transition metal oxides such as $\mathrm{TiO}_{2}$ provide high capacitance [2]. All discharge curves for sheets were obtained at $0.4 \mu \mathrm{A} / \mathrm{mm}^{2}$.

Another quantitative method for assessing the performance of capacitors is the Ragone plot. The Ragone plot of a capacitor shows the relation between the energy-storage and power capabilities of the capacitor. The Ragone plots of capacitor sheets made with and without CNT are shown in Figure 3(d). The plots show a general trend that the energystorage and power capabilities of capacitor sheets made with CNT are significantly larger than those made without CNT. In particular, the energy-storage capabilities show a 5-9 times increase as the result of the inclusion of CNT. Previously, the Ragone plot of PANI/CNT composite capacitor sheets [6] shows a maximum specific energy of $0.6 \mathrm{Wh} \mathrm{kg}^{-1}$ and a maximum power capability of $0.2 \mathrm{~kW} \mathrm{~kg}^{-1}$, which are to be compared to the respective maximum values of $17 \mathrm{Wh} \mathrm{kg}^{-1}$ and $5 \mathrm{~kW} \mathrm{~kg}^{-1}$ obtained in the present work. The results obtained in the present work indicate the effect of the nanomaterials on improving the energy and power capabilities for supercapacitor applications.

To probe the charging/discharging processes occurring in the nanocomposite materials, ac impedance spectroscopy 

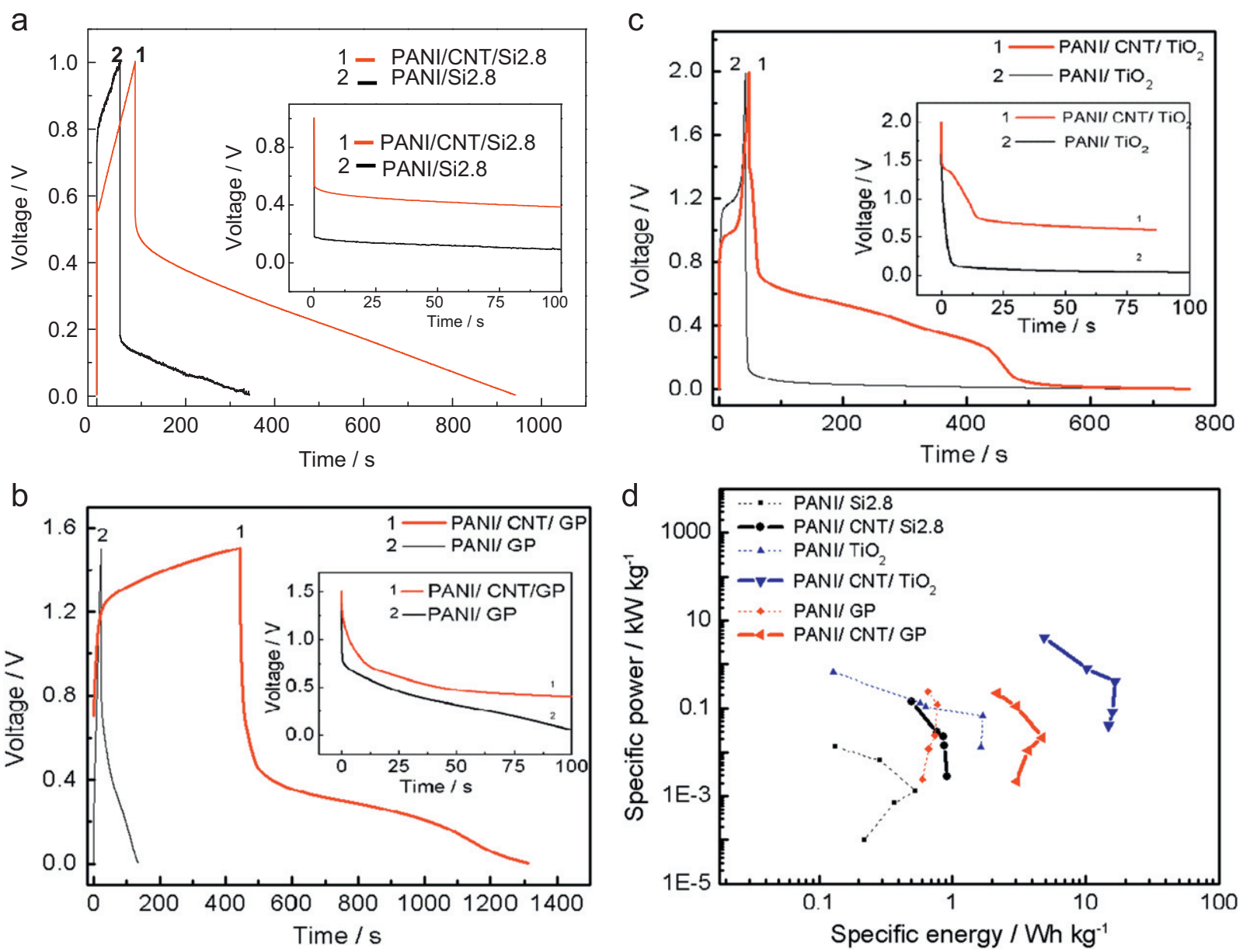

Figure 3 (a)-(c) Charging/discharging characteristics of nanocomposite-based capacitor sheets with and without CNT. (d) Ragone plots of capacitor sheets with and without CNT.
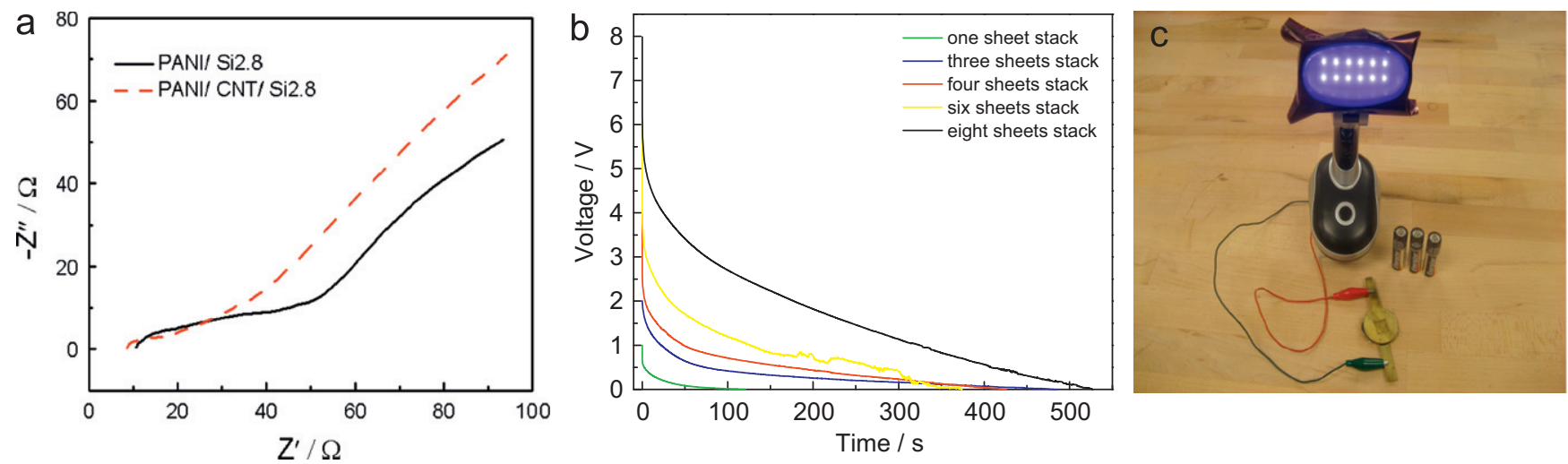

Figure 4 (a) AC impedance spectra of the PANI/Si2.8 and PANI/CNT/Si2.8 capacitor sheets. (b) Discharging characteristics of a stack of PANI/CNT/Si2.8 capacitor sheets. (c) A portable LED lamp powered by a stack of 8 capacitor sheets.

[13] has been performed with the capacitor sheets between $5 \mathrm{mHz}$ and $100 \mathrm{kHz}$. The impedance spectra of a PANI/Si2.8 capacitor sheet and a PANI/CNT/Si2.8 capacitor sheet are shown in Figure 4(a). The spectra reveal weak semi-circle structures in the high frequency parts of the spectra, indicating that the polarization resistance of the PANI/ Si2.8 capacitor sheet is about $40 \Omega$ while that of the PANI/ CNT/Si2.8 is about $10 \Omega$ The other two types of capacitor sheets show similar effect. The reduced polarization resistances as the result of the inclusion of CNT could be due to the increased porosity in the nanocomposite materials created by the presence of CNT.

The potential of the nanocomposite-based supercapacitor sheets in illumination applications has been demonstrated with a portable light-emitting diodes (LEDs) lamp, which requires three $A \mathrm{~A}$ batteries to provide $4.5 \mathrm{~V}$ to drive an assembly of 12 white LEDs for its operation. Since a single capacitor sheet provides only about $0.8 \mathrm{~V}$, stacks of 
capacitor sheets were used in order to achieve high operating voltage. Figure 4(b) shows the discharging characteristics of PANI/CNT/Si2.8 capacitor stacks of up to 8 sheets. The operating voltage appears to increase from $0.8 \mathrm{~V}$ to $6 \mathrm{~V}$ (where discharging starts) as the number of sheet is increased from 1 to 8 . Figure 4(c) shows the operation of the LED lamp.

\section{Conclusions}

Nanomaterials such as carbon nanotubes, silicon and titanium oxide particles and grapheme flakes have been incorporated into the conducting polymer polyaniline to form nanocomposite materials. Electrochemical characterizations of the nanocomposite materials that were deposited on single electrodes indicated significantly improved electrode capacitance for supercapacitor applications. The nanocomposite materials have been used to construct flexible supercapacitor sheets, which showed enhanced charge-storage and power capabilities as the result of the presence of the nanomaterials. The inclusion of carbon nanotubes in the nanocomposite materials was observed to reduce the equivalent series resistance of the materials due to its high conductivity. Stacks of capacitor sheets were used to power an LED lamp. The experimental results of the present work indicate the potential of the nanocomposite materials and the capacitor sheet in portable illumination applications.

\section{References}

[1] C.N.R. Rao, A. Muller, A.K. Cheetham (Eds.), Nanomaterials Chemistry, Wiley-VCH, Weinheim, 2007.

[2] P.J. Hall, et al., Energy and Environmental Science 3 (2010) 1238-1251.

[3] E. Frackowiak, V. Khomenko, K. Jurewicz, K. Lota, F. Beguin, Journal of Power Sources 153 (2006) 413-418.

[4] K. Jurewicz, S. Delpeux, V. Nertagna, F. Beguin, E. Frackowiak, Chemical Physics Letters 347 (2001) 36-40.

[5] Q. Liu, M.H. Nayfeh, S.-T. Yau, Journal of Power Sources 195 (2010) 3956-3959.

[6] Q. Liu, M.H. Nayfeh, S.-T. Yau, Journal of Power Sources 195 (2010) 7480-7483.

[7] G. Belomoin, J. Therrien, M. Nayfeh, Applied Physics Letters 77 (2000) 779-781.

[8] C.-C. Hu, E. Chen, J.-Y. Lin, Electrochimica Acta 47 (2002) 2741-2749.

[9] R.L. Hand, R.F. Nelson, Journal of American Chemical Society 96 (1974) 850-860.

[10] A. Burke, Journal of Power Sources 91 (2000) 37-50.

[11] E. Frackowiak, Physcal Chemistry Chemical Physics 9 (2007) 1774-1785.
[12] R. Kotz, M. Carlen, Electrochimica Acta 45 (2000) 2483-2498.

[13] B.E. Conway, Electrochemical Supercapacitors, Kluwer Academic, New York, 1999. 